the practice of the Mulago Hospital." From Makerere University College, Uganda, Billinghurst and Welchman ${ }^{4}$ reported the first detailed account of ulcerative colitis developing in four Africans in tropical Africa. Inspection of the medical records of the Lagos University Teaching Hospital for 1962-8 showed only one patient with a diagnosis of ulcerative colitis that could be substantiated. ${ }^{5}$ Tandon $e t a l^{6}$ reported 65 cases of ulcerative colitis in two and a half years in populous northern India and concluded that the disease was not as rare as was thought in Indians. Chuttani et al, ${ }^{7}$ who studied the medical records of leading hospitals in different parts of India for 1955-60, also showed that ulcerative colitis was not rare in that part of the world, but they claimed that it was a mild disease when compared with that in Western series. Wye Poh Fung et $a l^{8}$ from Singapore, where $75^{\circ}$ of the population of 2 million are Chinese and $8^{\circ}$. Indian, documented 10 patients, five Chinese and five Indians, with non-specific ulcerative colitis; this was probably the first report of this disease in Chinese. Terry and Raje $^{9}$ recently described 32 unpublished cases of ulcerative colitis in Jamaica.

The reported pattern for Crohn's disease seems to be more clear-cut. Only five cases of Crohn's disease were observed in the Harlem Hospital during 1936-49, ${ }^{11}$ and an epidemiological and demographic study of inflammatory bowel disease based on a computerised file of all patients followed up at the University of Chicago found only 23 cases of Crohn's disease in blacks among 1557 patients with inflammatory bowel disease. ${ }^{12}$ Crohn's disease is also rare in Indians in India and Pakistan. ${ }^{13}$

Trinidad and Tobago is a very cosmopolitan island with a population of 1.2 million people, $42^{\circ}{ }_{0}$ of whom are Negroes,
$40 \%$ Indians, $0.9 \%$ Chinese, $1 \%$ white, and $14 \%$ mixed. There seems to be no significant ethnic preference for these diseases among the Negroes and Indians of the island, suggesting perhaps a common environmental factor. The course of inflammatory bowel disease in Trinidadians cannot be described as mild, for in many cases the disease was extensive and the complications severe. Inflammatory bowel disease does occur in West Indians of both African and Indian stock who have not migrated to the United Kingdom and so environmental factors abroad do not necessarily play a part in the pathogenesis of this disease in these people.

\section{References}

${ }^{1}$ Melrose, A G, Gastroenterology, 1955, 29, 1055.

2 O'Donoghue, D P, and Clark, M L, British Medical fournal, 1976, 2, 796.

3 Trowell, H C, Non-infective Disease in Africa. London, Arnold, 1960.

${ }^{4}$ Billinghurst, J R, and Welchman, J M, British Medical fournal, 1966, $1,211$.

5 Naish, J M, Batchvarov, B D, and Lawoyin, V L, Gut, 1970, 11, 38.

6 Tandon, B N, et al, Gut, 1965, 6, 448.

7 Chuttani, H K, et al, British Medical fournal, 1967, 4, 204.

${ }^{8}$ Wye Poh Fung, et al, Medical fournal of Australia, 1971, 2, 361.

9 Terry, S, and Raje, D, paper read at 22nd Scientific Meeting of the Commonwealth Caribbean Medical Research Council, Belize, 1977.

${ }^{10}$ Crohn, B B, Ginsburg, L, and Oppenheimer, G D, fournal of the American Medical Association, 1932, 99, 1323.

${ }^{11}$ Marks, J A, and Fink, S, Gastroenterology Review, 1949, 16, 623.

12 Samuels, A D, et al, Digestive Diseases, 1974, 19, 156.

13 Woodruff, A W, editor, Alimentary and Haematological Aspects of Tropical Diseases, p 76. London, Arnold, 1970.

(Accepted 20 fuly 1979)

\title{
Finger clubbing in inflammatory bowel disease: its prevalence and pathogenesis
}

\author{
G KITIS, H THOMPSON, R N ALLAN
}

British Medical fournal, 1979, 2, 825-828

\section{Summary and conclusions}

Finger clubbing, measured objectively by using the hyponychial angle, was present in 75 out of $200(38 \%)$ patients with Crohn's disease, 15 out of $103(15 \%)$ with ulcerative colitis, and two out of $24(8 \%)$ with proctitis. In Crohn's disease and ulcerative colitis the hyponychial angle was significantly correlated with both disease activity and the extent of fibrosis in the resected specimens from 47 surgically treated patients. The prevalence of finger clubbing in patients with macroscopic disease within the area of the gut innervated by the vagus nerve was significantly higher than that in patients in whom the disease was confined to the distal colon and rectum. Finger clubbing in patients with Crohn's disease tended to regress after resection of macroscopic disease.

Gastroenterology Unit, General Hospital, Birmingham B4 6NH G KITIS, MRCP, research fellow

R N ALLAN, MD, MRCP, consultant physician

University of Birmingham, Birmingham

H THOMPSON, MRCPATH, reader in pathology
It is concluded that finger clubbing is significantly commoner in Crohn's disease than ulcerative colitis. The focal stimuli for finger clubbing include mucosal inflammatory change and fibrosis mediated by the vagus and possibly other autonomic pathways acting as the afferent arc of a finger-clubbing reflex.

\section{Introduction}

Trousseau ${ }^{1}$ suggested the term finger clubbing for changes in the fingers first described by Hippocrates. ${ }^{2}$ Its pathogenesis remains unknown. The clinical assessment of finger clubbing is often unreliable and subject to errors made by different or even the same observers. ${ }^{3}$ Measurements taken from digital casts have shown that the hyponychial and profile angles provide the best objective evaluation of finger clubbing. ${ }^{4}$ Of the two, the hyponychial angle, which also incorporates the profile angle, is the more reliable (see fig 1). The hyponychial and profile angles can now be measured clinically simply and effectively with the finger-clubbing shadowgraph. ${ }^{5}$ The normal range has been established in adults and children, and the method used in studies of finger clubbing in children with thalassaemia, ${ }^{6}$ cystic fibrosis, bronchial asthma, and congenital heart disease.

The association between finger clubbing and inflammatory bowel disease is well recognised, ${ }^{8-12}$ and patients with both conditions provide a useful model when studying pathogenesis. 
The reported prevalence of finger clubbing in Crohn's disease varies from $31.5 \%$ in a retrospective review of medical records ${ }^{\circ}$ to $58 \%$ in a prospective clinical study. ${ }^{10}$ Three retrospective reviews suggest that the prevalence of finger clubbing in ulcerative colitis varies between 4 and $50 \%{ }_{0}^{0} 1112$

Clinical studies of patients with Crohn's disease suggest that finger clubbing is commonly associated with active disease. ${ }^{10}$ In addition finger clubbing is particularly common in patients with intrathoracic tumours, when there is a noticeably fibrous stroma. ${ }^{13}$ This observation led to the suggestion that fibrosis may be important in the pathogenesis of finger clubbing in Crohn's disease. ${ }^{9}$ Rapid resolution of finger clubbing and hypertrophic osteoarthropathy was observed when treatment of "inoperable bronchial carcinoma" was confined to intrathoracic vagotomy for intractable pain. ${ }^{14}$ This raised the possibility that the vagus nerve may play a part as an afferent arc of a finger-clubbing reflex. ${ }^{15-18}$ The vagus nerve innervates the small and large intestine as far as the mid-transverse colon. ${ }^{19}$ In three clinical studies of ulcerative colitis only one patient had finger clubbing when the macroscopic disease was confined to the distal large bowel. ${ }^{911} 12$ The efferent pathway of the finger-clubbing reflex has not been established, but the focal changes observed in the digits include increased blood flow 8162021 and amount of connective tissue. ${ }^{22}$

We aimed in this study at evaluating the prevalence of finger clubbing in inflammatory bowel disease and examining the role in pathogenesis of fibrosis, vagal innervation, disease activity, and disease duration.

\section{Patients and methods}

We measured the hyponychial and profile angles using a fingerclubbing shadowgraph (fig 1). The normal range was determined

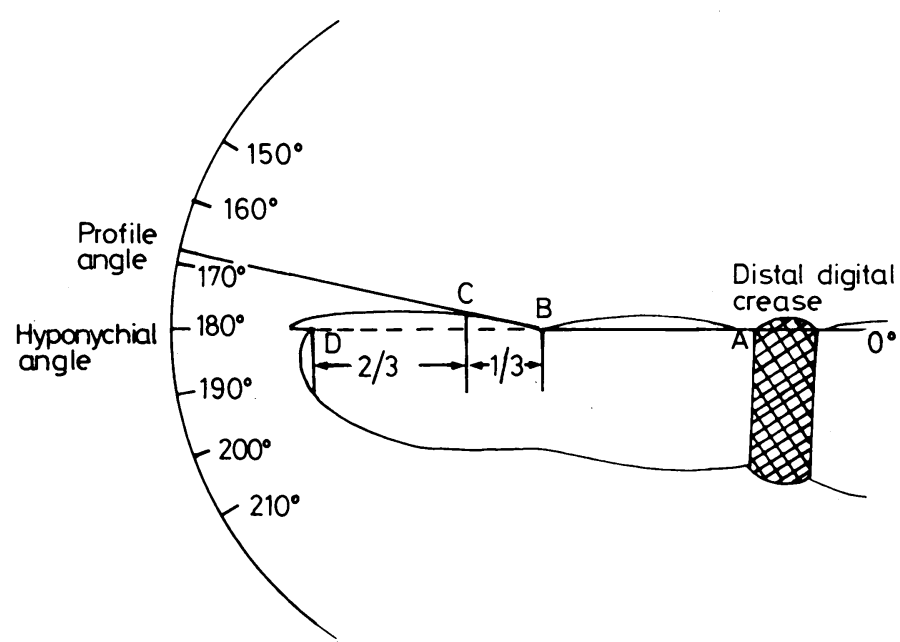

FIG 1-Representation of method of measuring profile and hyponychial angles. The profile angle lies between a line from the distal skin crease through the cuticle to a point one-third of the axial distance from the cuticle to the finger tip (ABC). The hyponychial angle lies between the points $\mathrm{ABD}$. The point $\mathrm{D}$ is the hyponychium (thickened stratum corneum of epidermis lying under the free edge of the nail).

in 116 healthy hospital employees with no chest symptoms, in 51 of whom duplicate measurements were obtained by the same observer at least a week later. The presence of finger clubbing was defined as an increase in the hyponychial angle of more than 1.65 SD from the control mean, thus reaching significance $\left(95^{\circ}\right.$ o confidence limits) according to the single-sided normal distribution function. The profile angle was used in a few patients when the hyponychial angle could not be measured because of nail biting.

We selected at random 200 patients with Crohn's disease, 103 with ulcerative colitis, and 24 with proctitis from hospital inpatients and those attending the inflammatory bowel disease clinic. None had any chest symptoms, and chest radiographs were all normal. Disease activity was assessed by changes in haemoglobin, serum albumin, and serum seromucoid concentrations graded on a scale from 0 , when all the indices were normal, to 9 , when all the indices were severely abnormal. ${ }^{23} 24$ The degree of fibrosis was measured in surgical specimens from 35 patients with Crohn's disease and 12 with ulcerative colitis. The macroscopic assessment included estimating the length of diseased gut and the presence of adhesions, stenosis, stricture, fistula, or abscesses. Microscopic assessment included estimating the extent of fibrosis in the submucosal and subserosal layers in multiple histological sections stained with haematoxylin and eosin, reticulin, and van Gieson stains.

The duration of disease was defined as the time between the onse of symptoms and the date when finger clubbing was measured.

The site of macroscopic disease was defined by radiological or sigmoidoscopic examination and at laparotomy. The patients were divided into four groups: those in whom all the macroscopically diseased gut had been resected; those in whom the macroscopic disease lay within the distribution of the vagus nerve; those in whom the macroscopic disease was distal to the splenic flexure and hence outside the innervation of the vagus; and those with macroscopic disease at both sites. Serial postoperative measurements of finge clubbing were made in 24 patients with Crohn's disease and five with ulcerative colitis. Improvement was defined as improvement in the hyponychial angle of at least three degrees.

The statistical analysis was done using Student's $t$ test with one-sided normal distribution function, the $\chi^{2}$ test, and the coefficient of correlation.

\section{Results}

Figure 2 shows the distribution of finger clubbing as measured by the hyponychial angle in the control subjects and patients with Crohn's disease. Table I shows the mean profile and hyponychial angles in the healthy control subjects; the duplicate measurements in 51 of these controls confirmed that the measurement was reproducible. The mean hyponychial angle in this group was $177.9^{\circ}$, so we defined

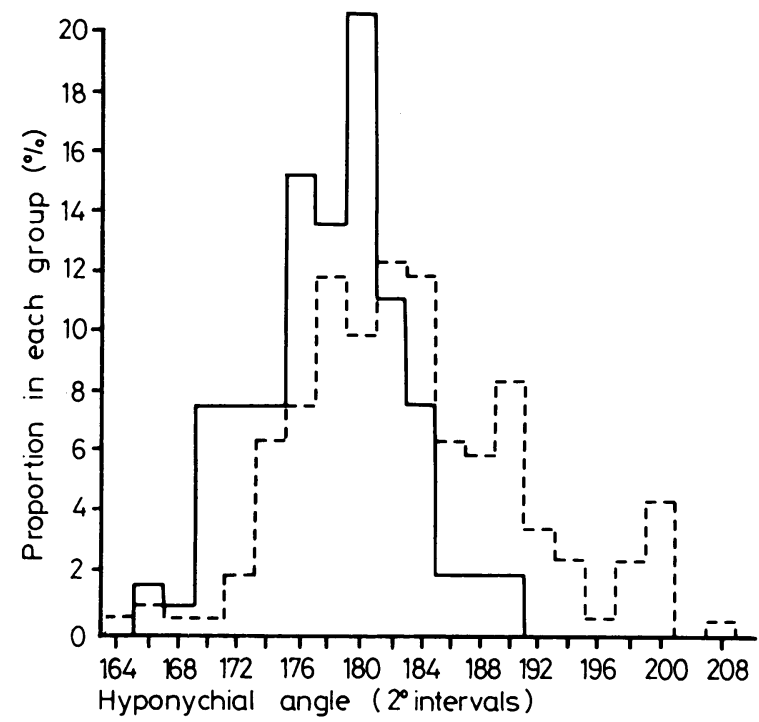

FIG 2-The distribution of finger clubbing as measured by the hyponychial angle in healthy subjects ( $n=116$-solid line) and patients with Crohn's disease $(n=200$-dashed line) plotted at $2{ }^{\circ}$ intervals.

TABLE I-Mean $( \pm S D)$ profile and hyponychial angles in normal subjects

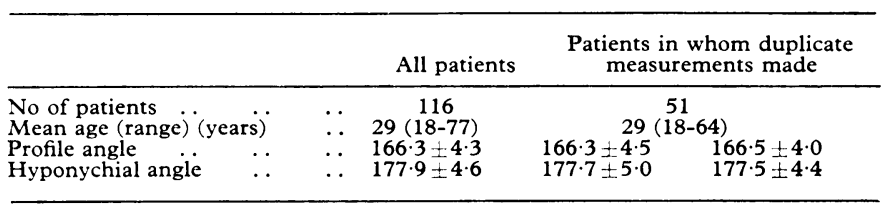


the presence of finger clubbing as a hyponychial angle greater than $186^{\circ}$ (>-1.65 SD from the control mean).

The prevalence of finger clubbing was $37.5 \%$ in patients with Crohn's disease, $14.5 \%$ in those with ulcerative colitis, and $8 \%$ in those with proctitis (table II). The prevalence of finger clubbing was significantly higher in Crohn's disease than ulcerative colitis $(\mathrm{P}<0.001)$.

Most patients with finger clubbing had laboratory evidence of active disease. Finger clubbing in both Crohn's disease and ulcerative

TABLE II-Prevalence of finger clubbing in patients with inflammatory bowel disease

\begin{tabular}{lcccc}
\hline & $\begin{array}{c}\text { No of } \\
\text { patients }\end{array}$ & M:F & $\begin{array}{c}\text { Mean age (range) } \\
\text { (years) }\end{array}$ & $\begin{array}{c}\text { No ( }(0 ; 0) \text { with } \\
\text { finger clubbing }\end{array}$ \\
\hline Crohn's disease & 200 & $88: 112$ & $44 \cdot 5(14-82)$ & $75(37 \cdot 5)$ \\
Ulcerative colitis & 103 & $51: 52$ & $45 \cdot 3(16-89)$ & $15(14.5)$ \\
Proctitis & 24 & $13: 11$ & $42.0(19-76)$ & $2(8 \cdot 3)$ \\
\hline
\end{tabular}

Crohn's disease $v$ ulcerative colitis: $\chi^{2}=15 \cdot 705, P<0 \cdot 0005$

TABLE III-Prevalence of finger clubbing according to whether disease active or inactive

\begin{tabular}{lccc}
\hline $\begin{array}{c}\text { Finger } \\
\text { clubbing }\end{array}$ & $\begin{array}{c}\text { No with } \\
\text { active disease }\end{array}$ & $\begin{array}{c}\text { No with } \\
\text { inactive disease }\end{array}$ & Significance \\
\hline $\begin{array}{l}\text { Present } \\
\text { Absent }\end{array}$ & 53 & $\begin{array}{c}\text { Crohn's disease } \\
22\end{array}$ \\
$\begin{array}{l}\text { Present } \\
\text { Absent }\end{array}$ & 38 & $\begin{array}{c}82 \\
\text { Ulcerative colitis } \\
6\end{array}$ & $x^{2}=26.66, P<0.001$ \\
\hline
\end{tabular}

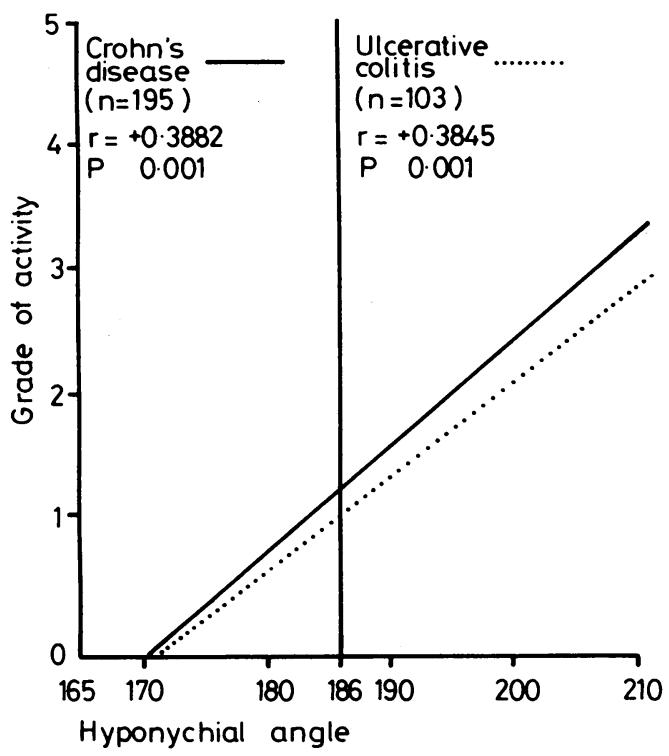

FIG 3-Correlation coefficients in patients with ulcerative colitis and Crohn's disease between grade of disease activity based on changes in haemoglobin, serum albumin, and serum seromucoids concentrations $(0=$ all indices normal; $9=$ all indices grossly abnormal) and finger clubbing as measured by the hyponychial angle. colitis was significantly commoner in those patients with active compared with inactive disease $(P<0.001$ and $P<0.02$ respectively; table III). The hyponychial angle and the grade of activity were significantly correlated in both Crohn's disease and ulcerative colitis ( $P<0.001$; fig 3 ).

In the study of surgical specimens there was a significant correlation between the grade of fibrosis in the resected specimen and the hyponychial angle $(P<0.001$; fig 4$)$. Most of the patients undergoing surgical resection had evidence of active disease. In 13, however, the laboratory values were normal. Finger clubbing was present in four of the six with extensive fibrosis but in only one of the seven with minimal fibrosis.

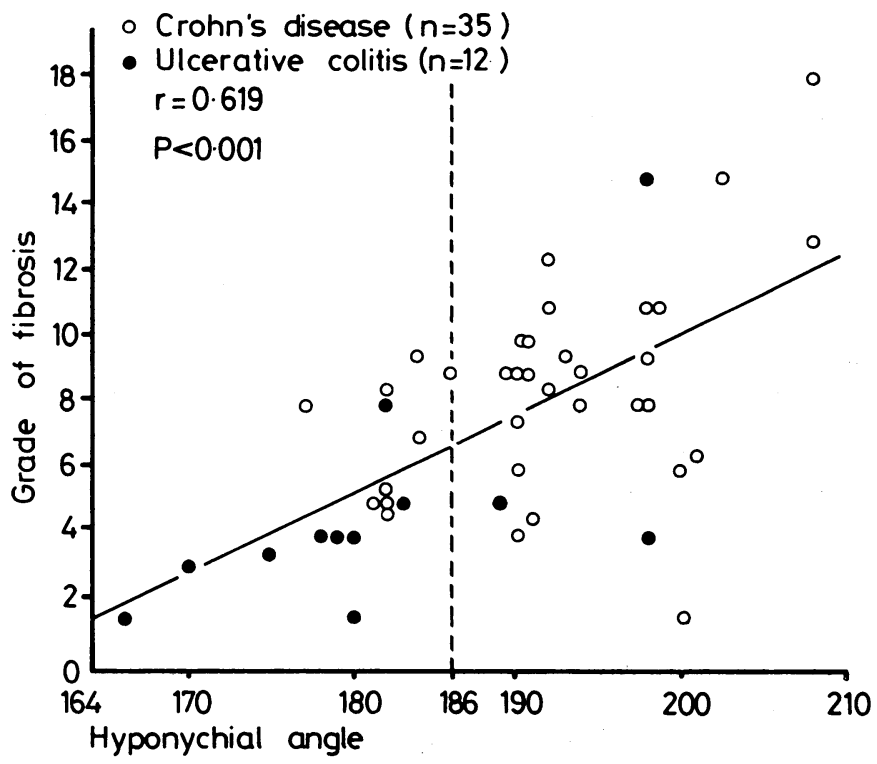

FIG 4-Correlation coefficient in patients with ulcerative colitis and Crohn's disease between extent of fibrosis in the resected specimen (see text for definition) and finger clubbing as measured by the hyponychial angle.

There was no significant correlation between the hyponychial angle and the duration of disease.

Table IV shows the prevalence of finger clubbing and the site of macroscopic disease. In both Crohn's disease $(P<0.01)$ and ulcerative colitis $(P<0.02)$ there was a significant difference in the prevalence of finger clubbing between patients with macroscopic disease within and beyond the site of the vagal innervation and patients with distal disease alone. Finger clubbing was present in only five patients in whom Crohn's disease was confined to the distal colon and rectum, of whom three had recently undergone resections for the disease elsewhere in the intestine and two had other disorders commonly associated with finger clubbing. When the results for Crohn's disease, ulcerative colitis, and proctitis were combined the prevalence of finger clubbing was significantly commoner in patients in whom the macroscopic disease was within the distribution of the vagus nerve than in those with distal colonic and rectal disease $(P<0.001)$. Finger clubbing was, however, present in 10 patients with distal disease, of whom three had no evidence of disease activity.

Finger clubbing persisted in 13 of the 73 patients with Crohn's disease and one of the 25 patients with ulcerative colitis in whom all the macroscopically diseased gut had been resected.

TABLE IV-Prevalence of finger clubbing in inflammatory bowel disease and its relation to site of macroscopic disease with particular reference to vagal innervation of gut (small intestine and large intestine as far as splenic flexure)

\begin{tabular}{|c|c|c|c|c|c|c|c|c|c|}
\hline \multirow[b]{2}{*}{$\begin{array}{l}\text { Site of macroscopic disease in } \\
\text { gastrointestinal tract }\end{array}$} & & \multicolumn{2}{|c|}{ Crohn's disease } & \multicolumn{2}{|c|}{ Ulcerative colitis } & \multicolumn{2}{|c|}{ Proctitis } & \multicolumn{2}{|c|}{ Total } \\
\hline & & No of patients & $\begin{array}{c}\text { No in whom } \\
\text { finger clubbing } \\
\text { present }\end{array}$ & No of patients & $\begin{array}{c}\text { No in whom } \\
\text { finger clubbing } \\
\text { present }\end{array}$ & No of patients & $\begin{array}{c}\text { No in whom } \\
\text { finger clubbing } \\
\text { present }\end{array}$ & No of patients & $\begin{array}{c}\text { No in whom } \\
\text { finger clubbing } \\
\text { present }\end{array}$ \\
\hline $\begin{array}{l}\text { Within distribution of vagus nerve } \\
\text { Distal to distribution of vagus nerve } \\
\text { No evidence of macroscopic disease }\end{array}$ & $\because$ & $\begin{array}{r}105 \\
22 \\
73\end{array}$ & $\begin{array}{r}57 \\
5 \\
13\end{array}$ & $\begin{array}{l}36 \\
42 \\
25\end{array}$ & $\begin{array}{r}11 \\
3 \\
1\end{array}$ & 24 & 2 & $\begin{array}{r}141 \\
88 \\
98\end{array}$ & $\begin{array}{l}68 \\
10 \\
14\end{array}$ \\
\hline Totals & & 200 & 75 & 103 & 15 & 24 & 2 & 327 & 92 \\
\hline
\end{tabular}


Twenty-four patients with Crohn's disease and preoperative evidence of finger clubbing were reassessed at intervals for one to 22 months after surgery. Thirteen improved, 11 with a decrease in the hyponychial angle of more than $5^{\circ}$. The earliest observed change occurred within one month after resection. Four patients showed no change one to 10 months after operation, although the laboratory investigations showed no evidence of active disease. A further seven patients, who had evidence of active disease elsewhere, recurrent disease, or other causes for finger clubbing, showed no change in the hyponychial angle. The postoperative data on patients with ulcerative colitis and finger clubbing are too few for further analysis.

\section{Discussion}

Most studies concerned with the pathogenesis of finger clubbing have been based on clinical observations. The fingerclubbing shadowgraph provides a reliable and reproducible method for measuring the profile and hyponychial angles, which are the best objective discriminators for evaluating finger clubbing. ${ }^{4}$ We defined finger clubbing as a hyponychial angle greater than $186^{\circ}$. In patients with hyponychial angles between $186^{\circ}$ and $189^{\circ}$ the clinical interpretation of the presence or absence of finger clubbing varied considerably, but when the hyponychial angle was greater than $189^{\circ}$ there was clear clinical evidence of finger clubbing. Serial measurements in patients with inflammatory bowel disease suggest that clinical finger clubbing represents one end of a range of changes in hyponychial angle that depend on fluctuations in the underlying disease process. Measurement of the hyponychial angle was not affected by age or sex. ${ }^{7}$

Our sample was biased by the inclusion of hospital inpatients. The true prevalence of finger clubbing in inflammatory bowel disease in an unselected sample is likely to be lower than that observed here. In Crohn's disease our observed prevalence of $37.5 \%$ is similar to the $31.5 \%$ observed by Perry et al ${ }^{9}$ but appreciably lower than the $58 \%$ reported by Fielding and Cooke. ${ }^{10}$ The reasons for this difference are not clear. In ulcerative colitis the observed prevalence of $14.5 \%$ is greater than the $5 \%$ reported. ${ }^{11} 12$ Both these earlier studies, however, were based on retrospective examination of medical records, which probably underestimates the true prevalence. This study confirms other reports that the prevalence of finger clubbing is significantly higher in patients with Crohn's disease than in those with ulcerative colitis.

Our finding that active disease is significantly associated with finger clubbing in both Crohn's disease and ulcerative colitis supports the suggestion of Fielding and Cooke that finger clubbing should be regarded as an index of activity of Crohn's disease $^{10}$ and the finding of Jalan et al that finger clubbing is associated with the severity of attacks of ulcerative colitis. ${ }^{12}$ Disease activity, while important in pathogenesis, is not the only factor, for finger clubbing may be found when there is no laboratory evidence of activity.

The extent of fibrosis in resected specimens was assessed macroscopically and microscopically because quantitative chemical analysis of collagen destroys the specimen. The highly significant correlation between the grade of fibrosis and the hyponychial angle in inflammatory bowel disease suggests that fibrosis is important in the pathogenesis of finger clubbing, which has already been observed in finger clubbing in intrathoracic tumours. ${ }^{13}$

Jalan $e t a l^{12}$ reported a significant correlation between finger clubbing and the duration of history in ulcerative colitis, but, like other workers, ${ }^{911}$ we were unable to confirm this.

The findings in this study are consistent with the vagus nerve acting as the afferent pathway of a finger-clubbing reflex, but the presence of finger clubbing in 10 out of 88 patients with disease distal to the splenic flexure, including patients with proctitis alone, suggests that the vagus nerve is not the sole afferent pathway. Moreover, finger clubbing was present in one out of five patients who had been treated by vagotomy for peptic ulcer. Good but indirect evidence exists that the vagus nerve is the afferent loop of a reflex causing finger clubbing, ${ }^{911} 1214-18$ but our findings suggest that other autonomic nerves can act in a similar way by responding to local stimuli such as inflammatory mucosal change and fibrosis.

The objective improvement in finger clubbing observed after resection confirms clinical observations in Crohn's disease. ${ }^{10}$

Thus these findings suggest that disease activity and fibrosis are important stimuli in an afferent pathway of a finger-clubbing reflex commonly mediated by the vagus nerve, though other autonomic pathways may also play a part. The efferent pathway of the reflex remains to be identified.

We thank the West Midlands Regional Health Authority Research Committee for financial support.

\section{References}

1 Trousseau, A, fournal des Connaissances Médico-Chirurgicales, 1834, $1,351$.

2 Adams, F, (trans), The Genuine Works of Hippocrates, vol 1, p 249. London, Sydenham Society, 1943.

3 Pyke, D A, Lancet, 1954, 2, 352.

4 Regan, G M, Tagg, B, and Thomson, M L, Lancet, 1967, 1, 350.

5 Bentley, D, and Cline, J, British Medical fournal, 1970, 3, 43.

6 Sinniah, D, et al, fournal of Pediatrics, 1978, 92, 597.

7 Bentley, D, Moore, A, and Shwachman, H, Lancet, 1976, 2, 164

${ }^{8}$ Mendlowitz, M, Medicine, 1942, 21, 269.

9 Perry, P M, Evans, G A, and Davies, J D, Diseases of the Colon and Rectum, 1972, 15, 278.

10 Fielding, J F, and Cooke, W T, Gut, 1971, 12, 442.

11 Young, J R, British Medical fournal, 1966, 1, 278.

12 Jalan, K N, et al, Gut, 1970, 11, 748.

13 Yacoub, M H, Simon, G, and Ohnsorge, T, Thorax, 1967, 22, 226.

14 Flavell, G, Lancet, 1956, 1, 260.

15 Huckstep, R L, and Bodkin, P E, Lancet, 1958, 2, 343.

${ }_{16}$ Holling, H E, Brodey, R S, and Boland, H C, Lancet, 1961, 2, 1269.

17 Diner, W L, fournal of the American Medical Association, 1962, 181, 555.

18 Carroll, K B, and Doyle, L, Thorax, 1974, 29, 262.

19 Goyal, R K, in Gastrointestinal Disease, ed M H Sleisenger and J S Fordtran, p 162. London, W B Saunders, 1978.

20 Wilson, G M, Quarterly fournal of Medicine, 1952, 21, 201.

${ }^{21}$ Racoceanu, S N, et al, Annals of Internal Medicine, 1971, 75, 933.

22 Lovell, R R H, Clinical Science, 1950, 9, 299.

${ }^{23}$ Cooke, W T, et al, Gastroenterology, 1958, 34, 910.

24 Thaw, P A, Serum seromucoid and acute phase proteins in inflanımatory bowel disease. MSc thesis, University of Birmingham, 1978.

(Accepted 31 fuly 1979)

ONE HUNDRED YEARS AGO We reported many months ago that the hospitals were being raked for young lads who had just passed their examinations to volunteer as medical officers for the Zulu campaign, whither they were despatched in numbers without adequate preliminary training and without even having passed through a Netley course. The extreme unpopularity of the Army Medical Department with the medical profession of course impeded volunteering, even of the stamp with which the heads of the department were fain to be content, and we are not surprised to read in the correspondence of more than one journal such phrases as this: "Experienced surgeons are required; not the young apothecaries' lads now being sent out." Of course, the field-service includes a certain number of well experienced medical officers, very far, however, it is admitted, below the necessities of the force. It includes also a considerable number of quite young men, some of whom had failed to pass the examination necessary for admission to the medical service of the army. No doubt they have striven, and will strive, to do their best, and will fulfil their duties as medical officers in volunteer or in the regular service are wont to fulfil their duty, under whatever conditions they may be placed; but it is a lamentable reflection that the extreme mismanagement of the Army Medical Department has so reduced the efficiency and detracted from the popularity of that service that at the first touch of warfare, even on a limited scale and with a savage people, it is found to be thoroughly undermanned and quite inadequate to the demands upon it. (British Medical fournal, 1879.) 